\title{
LAS ESCUELAS RURALES DE UNA COMARCA LEONESA
}

Isabel Cantón Mayo

Facultad de Educación, Universidad de León

icanm@unileon.es

\section{RESUMEN}

La escuela es la casa de la infancia y es el lugar de la memoria infantil que actúa como tercer educador después de la familia y los compañeros. Este artículo tiene por objetivo la recogida y documentación de los edificios escolares rurales situados en la comarca de la Maragatería. Se trata de una comarca en la provincia de León con su capital en Astorga que conserva ritos, trajes, espacios y tradiciones ancestrales muy definidos y particulares. El estudio de sus escuelas tiene también connotaciones específicas patrimoniales y contextuales. Se ha usado el método etnográfico para su elaboración. Los resultados, considerando su estructura y demás elementos arquitectónicos nos han permitido realizar una categorización de las mismas en función de la complejidad que presentan sus construcciones en: escuelas básicas antiguas (edificaciones simples de un aula y una sola planta); escuelas de balconada (las más frecuentes en la Maragatería, son de planta y piso y tienen abajo el aula y arriba la vivienda del docente); escuelas fortaleza (de planta y piso, robusta construcción, pocas ventanas, en piedra y mampostería); escuelas de torre o peineta (edificios esbeltos y esmerados con piedra y ladrillo, que se rematan en una torre con o sin reloj, o bien con una peineta en su parte frontal y suelen ser de indiano) y, finalmente, escuelas estándar de la posguerra, (de ladrillo, muy similares a las de otras partes de España, funcionalistas y sin adornos).

Palabras clave: Escuelas antiguas. Patrimonio escolar. Escuelas rurales.

\section{RURAL SCHOOLS IN A LEONESE REGION}

\begin{abstract}
School is the home of childhood and is the place of childhood memory that acts as the third educator after family and peers. This article aims to collect and document rural school buildings located in the Maragatería region. It is a region in the province of León with its capital in Astorga that preserves rites, costumes, spaces and ancestral traditions very defined and particular. The study of their schools also has specific heritage and contextual connotations. The ethnographic method has been used for its elaboration. The results, considering its structure and other architectural elements have allowed us to categorize them according to the complexity of their constructions in: ancient basic schools (simple one-room and one-storey buildings); balcony schools (the most common in the Maragatería, are floor and floor and have the classroom below and the teacher's house above); fortress schools (floor and floor, robust construction, few windows, in stone and masonry); tower or comb schools (slender and painstaking buildings with stone and brick, which are finished off in a tower with or without a clock, or with a comb on the front and are usually made of indiano) and, finally, standard post-war schools, (brick, very similar to those in other parts of Spain, functionalists and unadorned).
\end{abstract}

Rev. Iberoam. Patrim. Histórico-Educativo, Campinas (SP), v. 05, p. .1-13, e019028, 2019. 
Keywords: Old schools. School heritage. Rural schools.

\section{AS ESCOLAS RURAIS DE UMA COMARCA LEONESA}

\section{RESUMO}

A escola é a casa da infância e é o lugar da memória infantil que atua como terceiro educador depois da família e companheiros. Este artigo tem por objectivo a recolha e documentação dos edifícios escolares rurais situados na comarca da Maragateria. Trata-se de uma comarca na província de León com a sua capital em Astorga que conserva ritos, trajes, espaços e tradições ancestrais muito definidos e particulares. O estudo de suas escolas tem também conotações específicas patrimoniais e contextuais. Foi utilizado o método etnográfico para a sua elaboração. Os resultados, considerando sua estrutura e outros elementos arquitetônicos nos permitiram realizar uma categorização das mesmas em função da complexidade que apresentam suas construções em: escolas básicas antigas (edificações simples de uma sala de aula e um andar); escolas de balconada (as mais frequientes na Maragateria, são de andar e andar e têm abaixo a sala de aula e acima a casa do docente); escolas fortaleza (de andar e andar, construção robusta, poucas janelas, em pedra e alvenaria); escolas de torre ou penteneta (edifícios esbeltos e esmerados com pedra e tijolo, que são rematados numa torre com ou sem relógio, ou com uma presilha na sua frente e são geralmente de indiano) e, finalmente, escolas padrão do pós-guerra, (de tijolo, muito semelhantes às de outras partes de Espanha, funcionalistas e sem adornos).

Palavras-chave: Escolas antigas. Património escolar. Escolas rurais.

\section{LES ÉCOLES RURALES D'UNE RÉGION LEONAISE}

\section{RÉSUMÉ}

L'école est la maison de l'enfance et le lieu de la mémoire d'enfant qui agit comme troisième éducateur après la famille et les compagnons. Cet article a pour objectif la collecte et la documentation des bâtiments scolaires ruraux situés dans la région de la Maragateria. Il s'agit d'une région de la province de León avec sa capitale à Astorga qui conserve des rites, des costumes, des espaces et des traditions ancestrales bien définis et particuliers. L'étude de leurs écoles a également des connotations patrimoniales et contextuelles spécifiques. La méthode ethnographique a été utilisée pour son élaboration. Les résultats, compte tenu de leur structure et d'autres éléments architecturaux, nous ont permis de les classer en fonction de leur complexité qui présentent leurs constructions dans : écoles de base anciennes (bâtiments simples d'une salle de classe et un seul étage); écoles de balcon (les plus fréquents à la Maragateria, sont de plan et de plancher et ont en bas la salle de classe et en haut la maison de l'enseignant); écoles forteresse (de plan et de plancher, construction robuste, peu de fenêtres, en pierre et maçonnerie); écoles de tour ou peigne (bâtiments minces et soignés avec pierre et brique, qui se terminent dans une tour avec ou sans horloge, ou avec un peigne à l'avant et sont généralement d'indien) et enfin des écoles standard d'après-guerre, (en briques, très semblables à celles d'autres parties de l'Espagne, fonctionnalistes et sans ornements). 
Mots-clés: Écoles anciennes. Patrimoine scolaire. Écoles rurales

\section{ESCUELAS RURALES DE LA MARAGATERÍA}

El año 2018 fue declarado por la Unión Europea el Año Europeo del Patrimonio Cultural, por lo que es una oportunidad para celebrar la riqueza del patrimonio europeo y para propiciar el acercamiento a nuestros orígenes, recordando siempre la necesidad de custodiar nuestros bienes culturales para generaciones futuras y nuestro derecho, reconocido legalmente, a la protección del patrimonio. Las escuelas son el mejor símbolo patrimonial de cada pueblo, junto a su iglesia. También son el lugar de la memoria infantil de cada alumno cuando es adulto. El año 2014 se ha cumplido el trigésimo aniversario de la teorización de los "lieux de mémoire" por parte del historiador francés Pierre Nora, y nuestra memoria es la escuela. Loris Malaguzzi, ideólogo de la pedagogía de las escuelas de Reggio Emilia, señala que “el ambiente es el tercer educador.” El primer educador sería el grupo de compañeros con el que te educas". El segundo lo configuran todos los adultos, incluyendo en ese grupo de docentes, padres, familiares y todos los componentes de la comunidad educativa. El tercer educador es el de los ambientes en el que se desarrollan estas vivencias. Del mismo modo que los espacios pueden ser educativos y motivadores, pueden no serlo. Somos una especie animal caracterizada por aprender a lo largo de toda nuestra vida, necesitando un ambiente que favorezca el desarrollo. Como experiencia vital, estos procesos se desenvuelven en un ambiente tanto psicológico como físico, estando ambos íntimamente conectados. Ni el local, ni el material son la escuela; y, a pesar de ello, a mí me basta entrar en un local para saber si al pueblo le interesa la instrucción de sus hijos señala Luis Bello, en su Viaje por las Escuelas de España, 1926. Enseñarlo es también apasionante (CALAF, 2008).

Trabajar en la recuperación, inventario y documentación de las escuelas públicas rurales es una tarea a la vez hermosa y difícil: por el amor que le profesamos a los muros de la infancia, por ser la cuna de nuestra vida intelectual, por lo mucho que impregnó nuestro ser y por tantas otras cosas que tenemos que descubrir, es una tarea apasionante, bella y adictiva. También por lo poco que resta de ellas, por las pérdidas, por las horas de buceo en los archivos, en los pueblos en las gentes, por los favores que hay que pedir a personas y a instituciones, y por muchas cosas más, es una complicada tarea a la que sólo ya nos dedicamos idealistas y románticos. Es parte de lo que se ha llamado educación remedial (CANTÓN MAYO, 1996, 1999, 2006). Pero quizá la razón que 
más ha influido en la dedicación investigadora a este tipo de escuelas es la dimensión compensatoria. Las escuelas rurales han sido consideradas escuelas de segunda clase frente a las urbanas: con menores recursos, menores especialistas, menores y peores instalaciones. Por el contrario, han contado con y maestros en general más vocacionales, más entregados y más eficientes.

Las escuelas públicas rurales, Corchón (2 han desempeñado un papel crucial en la educación española: en primer lugar facilitando el acceso a la educación a una población que por su origen, localización y dificultades económicas no tenía posibilidad de recibir los bienes educativos. Pero además su papel en la igualdad de oportunidades ha sido crucial al insertar a la población rural en los estudios secundarios, fundamentalmente a partir de la Ley General de Educación de 1970. Esta educación rural y pobre se impartía en unos determinados edificios escolares que configuraban el ser y el porvenir de sus alumnos. Y sin embargo no se ha estudiado la incidencia del espacio escolar en los niños en sus primeras etapas, en sus juegos, en sus ideales, en sus vidas. Cossío et al. (1902) se ocuparon de las construcciones escolares en función de la población de cada lugar y pedían además el mejor maestro para la última escuela. Señalamos que el contexto es muy especial Rubio Pérez (2003), lo que también incide en las personas y en las escuelas.

Aquí nos ocupamos de las escuelas maragatas, una comarca bien delimitada en la provincia de León por varios motivos: están desapareciendo, son rurales y públicas y queremos preservar su memoria. 
Figura 1 - Mapa de la Maragatería en el Libro: Los Maragatos.

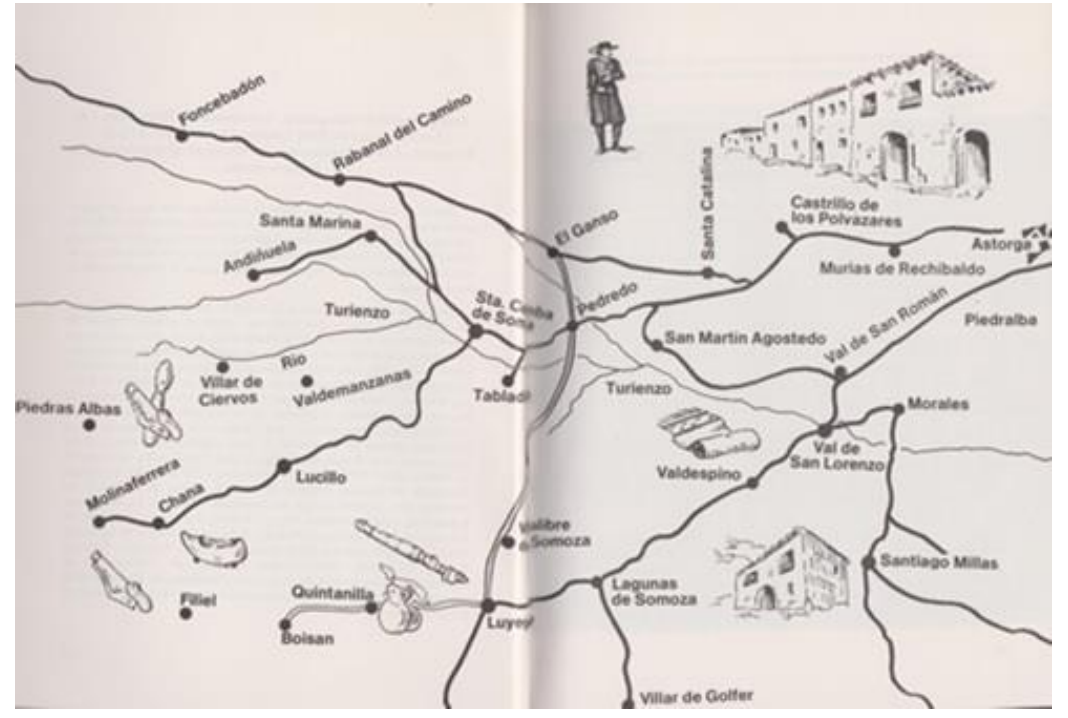

Fuente: Luis Alonso Luengo, libro citado en la bibliografía.

El Diccionario Geográfico-Estadístico de Madoz de 1845-50, delimitaba la maragatería como una comarca de la provincia de León, no lejos de Astorga por la parte sur, pero sin incluirla, situada entre los montes de Teleno y Foncebadón abarcando 36 pueblos que no enumera. Señala lo original y extraordinario del traje y la pobreza de la zona, por lo que los maridos hacían arriería y las mujeres cultivaban la tierra. En1888 el Diccionario Hispano-Americano de los Editores Montaner y Simón la sitúa en el mismo lugar aunque incluye en ella a la Valduerna y deja fuera a Filiel y a Chana, se cree que por error. Luis Alonso Luengo en su libro: Los Maragatos, de 1981, amplió la Maragatería a 44 pueblos incluyendo a Requejo, Rodrigatos, Argañoso, Busnadiego, Filiel, Chana, Piedras Albas y Pobladura de la Sierra.

Se divide en alta Maragatería, concentrada en torno al Ayuntamiento de Santa Colomba, y baja Maragatería con capital en Santiago Millas. También cuenta con una capital religiosa en Luyego de Somoza donde se encuentra la Patrona de la Maragatería: La Virgen de los Remedios.

Se tienen datos de la población de la Maragatería desde tiempos remotos. Los recientes descubrimientos por parte de Juan Carlos Campos (2012) de petroglifos megalíticos, datados por expertos en más de 5.000 años, están permitiendo conocer mejor las culturas prehistóricas de la región, aparte de haber revolucionado las teorías sobre Megalitismo en España, pues esta parte de la provincia de León no se encontraba dentro del área de las culturas megalíticas. Este autor encontró, entre otros megalitos, en junio de 2009 un menhir. Desde entonces esta línea de investigación tiene grandes aportes y defensores de la antigüedad maragata. Atribuye a Astorga la

Rev. Iberoam. Patrim. Histórico-Educativo, Campinas (SP), v. 05, p. .1-13, e019028, 2019. 
capital de la Maragatería, tema discutido por otros autores y que queda fuera de este estudio que solamente se ciñe a las escuelas rurales.

Lázaro Flores realiza una sintética historia de las construcciones escolares españolas señalando la primera etapa hasta 1920 sin intervención estatal directa en las construcciones escolares; una segunda etapa en 1920 donde se inicia la subvención a los edificios destinados a escuela y en 1928 también propone ampliarlas, aunque faltaron los recursos. En el quinquenio republicano aparece el primer plan de construcciones escolares con normativa específica en 1932 y 1934. Los primeros 12 años después de la Guerra Civil se paraliza la construcción de escuelas que se retoma con gran impluso en la Ley de Construcciones escolares (la única existente incluso hoy) de 1951-55. Varias de las escuelas documentadas en la Maragatería corresponden a esta época.

La metodología de este trabajo ha sido cualitativa-interpretativa y hermenéutica. Se ha consultado la información de los Archivos Históricos Provinciales y Nacionales, se ha realizado un trabajo de campo, visitando cada localidad, entrevistando a las personas que asistieron a las escuelas y recogiendo documentos gráficos. Además se ha recorrido la legislación al respecto buscando en el BOE la fecha de apertura y cierre de cada una de las escuelas, aunque no figuren en este trabajo por su extensión (CANTÓN, 2018).

Por el tipo de construcción hemos encontrado cuatro categorías de edificios escolares: el primer grupo lo constituyen las escuelas de modelo básico. Se trata de edificios de planta baja con un aula de dimensiones amplias para atender escolarmente hasta medio centenar de niños y niñas. Están orientadas de diversa forma con predominio del sur. No suelen tener dependencias anejas ni aseos, y cuando aparecen son añadidos más tardíamente. Estas escuelas son mixtas, atendidas en general por una maestra, aunque hubo periodos anteriores a la Guerra Civil en que también las servían maestros. Los recursos son muy básicos: algún mapa, la estufa inevitable en los largos inviernos y los libros que en un estrecho armario se contienen. Existen algunos anteriores a la Guerra y luego las dotaciones generales de libros de la posguerra, siguen las características de la escuela de menos de 500 almas del Ministerio, aunque con una sola aula en lugar de dos. Citamos las escuelas de: Rodrigatos de la Obispalía, de Turienzo de los Caballeros, Murias de Pedredo, San Martín del Agostedo, Villalibre, El Ganso, Brazuelo, Valdemanzanas, etc. 
Figura 2 - Casa de la maestra y escuela de Valdemanzanas y Escuela de Rodrigatos de la Obispalía.
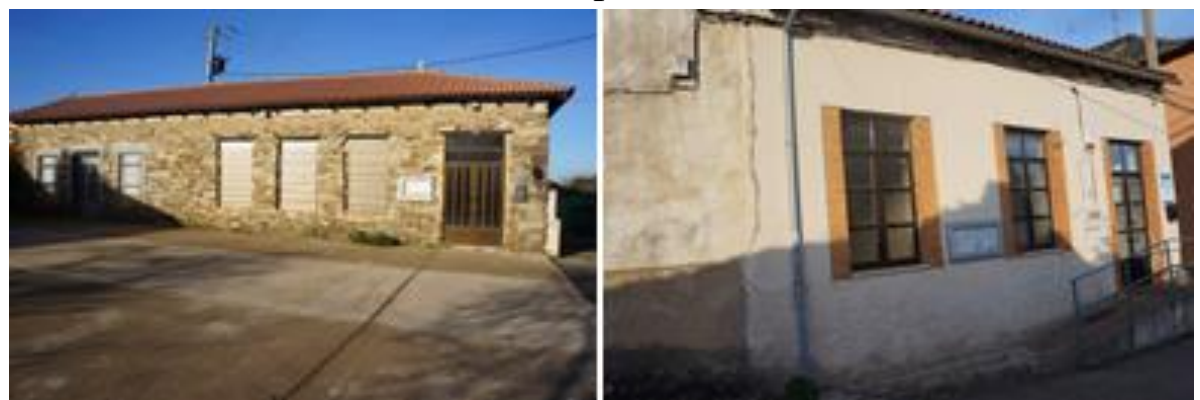

Fuente: Isabel Cantón Mayo.

Figura 3 - Escuela de Turienzo de los Caballeros y Villalibre de Somoza
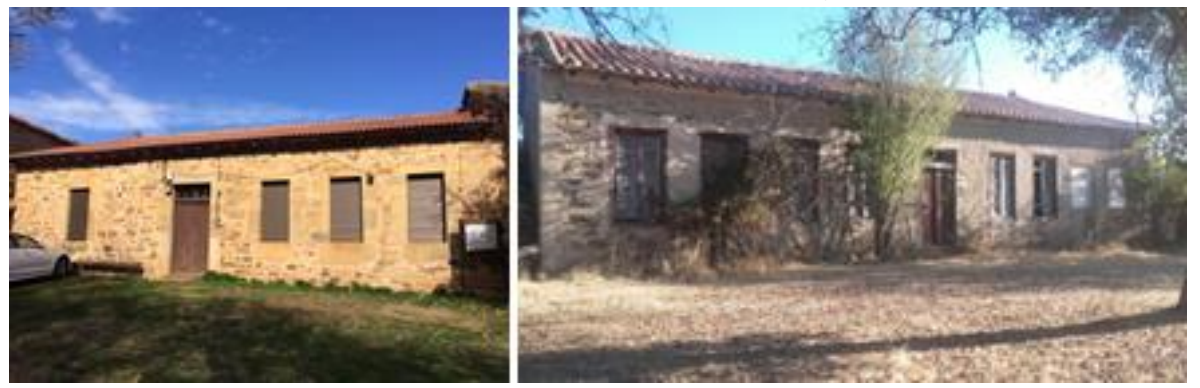

Fuente: Isabel Cantón Mayo y Archivo Histórico de León.

El segundo grupo lo constituyen las escuelas de corredor y balconada corrida en madera. Son de planta y piso, teniendo la planta baja para el aula y la parte superior para vivienda del maestro. El corredor con estupendas barandillas de madera de negrillo o chopo presentes en las edificaciones escolares maragatas más antiguas, también se conservan algunas puertas originales en las escuelas muy sólidas y algunas con puerta partida: la de abajo cerraba y la de arriba que hacía de ventana. La escalera suele ser exterior al amparo del mismo corredor en un extremo y este corredor hace de pasillo que no tienen ni las escuelas ni las casas maragatas. La vivienda de los maestros siempre en la parte superior (solo en un caso encontramos la vivienda abajo y el aula arriba). La filigrana en la madera que remata el corredor es variada pero no recargada y varía en cada lugar. La fachada principal está siempre orientada al sur o al oeste y bajo el corredor se abren las ventanas del aula, un poco mayores que las de arriba ya que se encontraban recogidas y bajo cubierta del corredor que servía de patio en los días de lluvia. El color es el mismo azul cobalto o verde fuerte pero ahora es más llamativo porque aparece en los dos pisos, pero no en el corredor. Algunas escuelas sí tienen ya aseos o dependencias anejas como leñeras o cuadras. Piedras Albas, Quintanilla de Combarros, Argañoso (que ya no existe) Pedredo, Chana, Tabladillo, etc.

Rev. Iberoam. Patrim. Histórico-Educativo, Campinas (SP), v. 05, p. .1-13, e019028, 2019. 
Figura 4 - Escuelas de Pedredo y Tabladillo.
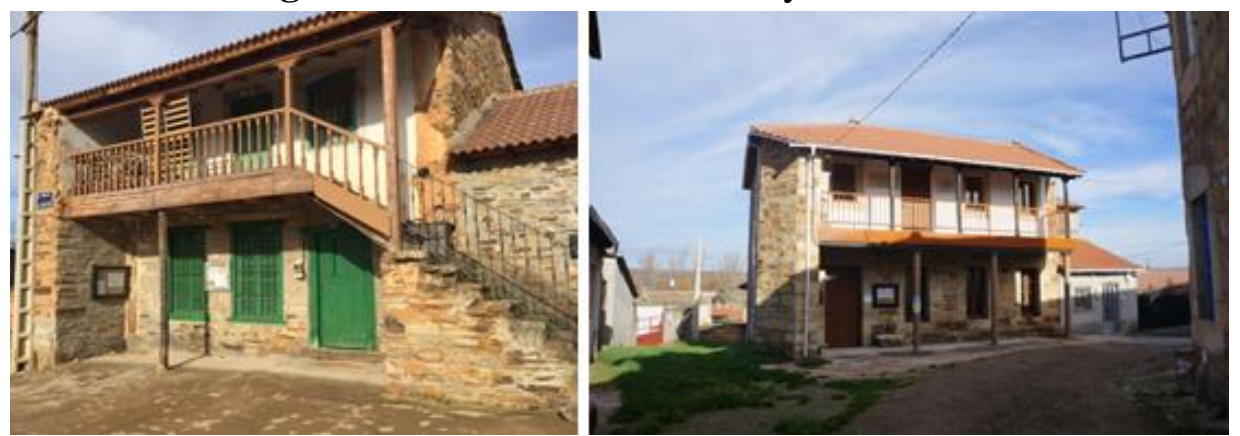

Fuente: Isabel Cantón Mayo.

Figura 5 - Escuelas de Piedras Albas y Quintanilla de Combarros.
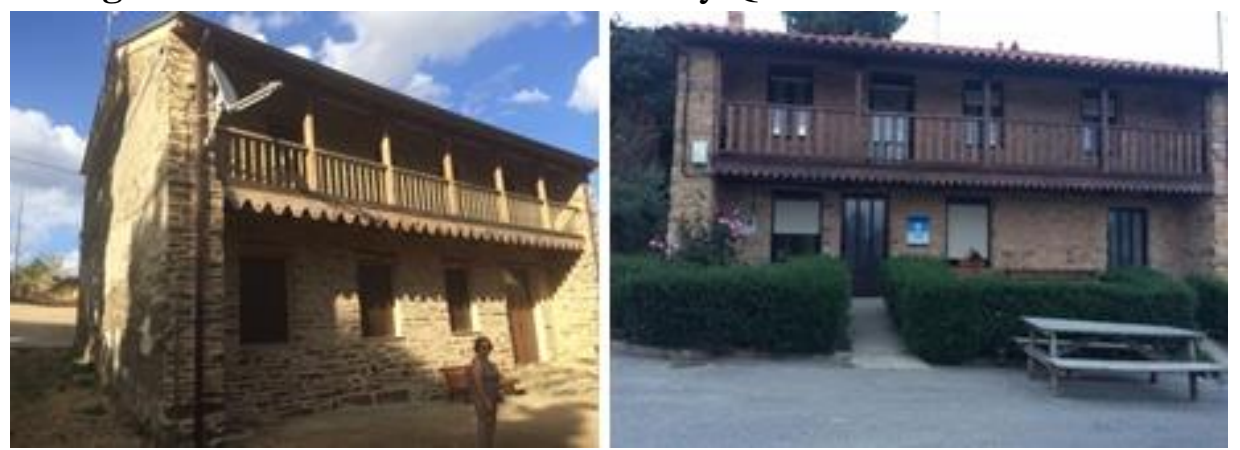

Fuente: Isabel Cantón Mayo.

El tercer grupo constituye la parte más original de las escuelas maragatas: majestuosas escuelas con torre y reloj. En su mayoría son escuelas de indiano ya que o bien el emigrante procedente del pueblo al que regresó rico, donó el edificio escolar, o bien si ya el edificio estaba construido, le donó una torre que lo ennoblece y engrandece. Esta especie de calvinismo sentimental de los indianos con el apoyo a la escuela obedecía al deseo de permanencia que también a veces fue recogido por los paisanos del lugar y son ellos mediante suscripción los que ponen placas en la escuela en memoria del benefactor indiano para que se anime a seguir contribuyendo y para colmar su satisfacción en las visitas al lugar de origen. Son ejemplo de ello las de las escuelas... En algunos casos han desaparecido, pero en la mayoría se mantienen. La diferencia entre los indianos maragatos y los asturianos no estriba en las acciones, sino en la potencia económica de unos y otros que hace que sean más humildes las aportaciones maragatas de indianos que las asturianas (CUENCA; FERNÁNDEZ, 2003). 
Son ejemplos de este tipo de escuelas las de Quintanilla de Somoza y la de Valdespino de Somoza. Son escuelas de los primeros años del siglo XX construidas en piedra y mampostería, con dos o más aulas, con buena dotación de recursos y no tienen corredor, sino que el edificio es compacto.

Figura 6: Escuela de Valdespino de Somoza y Escuela de Quintanilla de Somoza.
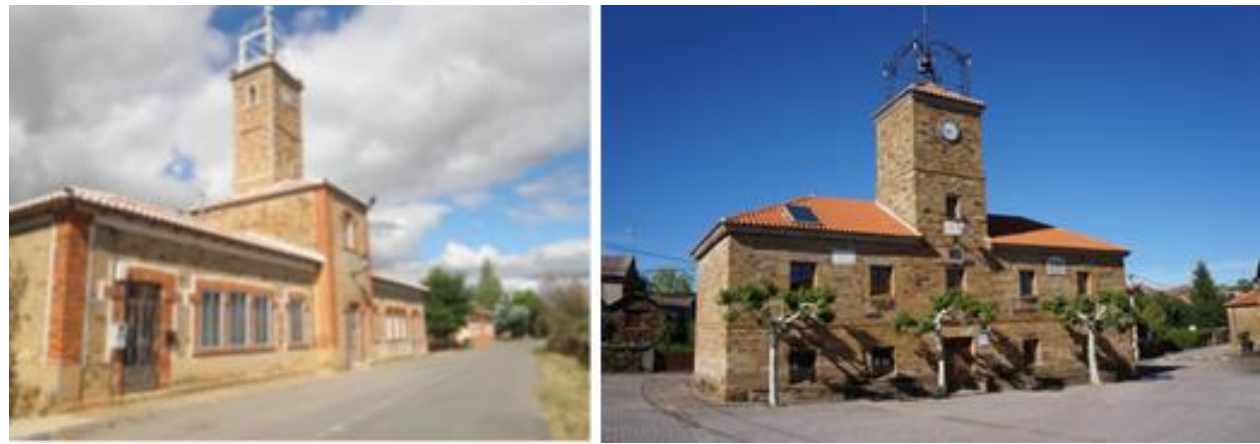

Fuente: Isabel Cantón Mayo y Archivo Histórico de León.

Figura 7 - Escuela de Santa Colomba de Somoza.

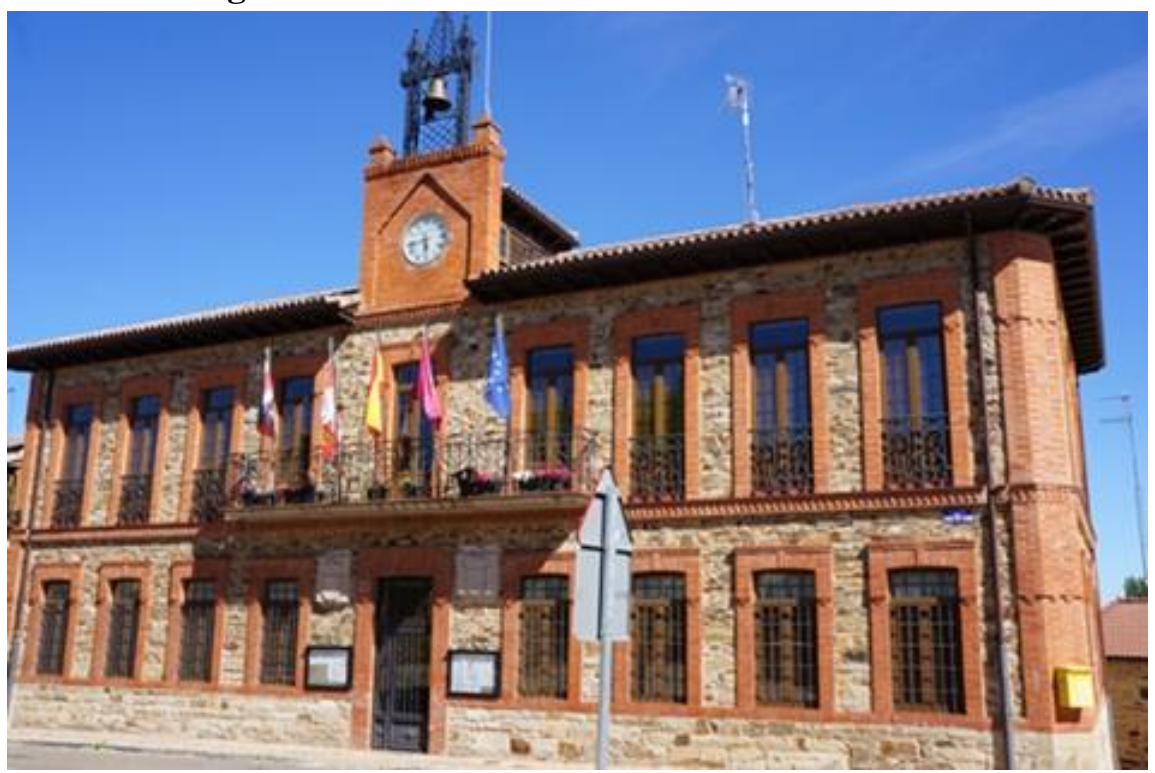

Fuente: Isabel Cantón Mayo y Archivo Histórico de León.

El cuarto grupo lo constituyen las llamadas escuelas-fortaleza por su imponente edificio, cerrado, con funciones casi defensivas, al igual que los castillos. Los muros son compactos, no hay adornos, pocas ventanas y mucha piedra, desafiando al tiempo y al espacio, con estructura poco definida y elementos arquitectónicos resistentes, lineales y definidos. Los campamentos romanos a veces ya eran auténticas fortalezas y más adelante en la reconquista los castillos fueron ejemplos

Rev. Iberoam. Patrim. Histórico-Educativo, Campinas (SP), v. 05, p. .1-13, e019028, 2019. 
de este modelo de construcción, que encontramos en las escuelas maragatas. Esta arquitectura está muy documentada en Aragón y Cataluña, pero poco en esta zona. Destacamos como ejemplo de escuelas-fortaleza las de Requejo-Pradorrey, Rabanal Viejo, Boisán, Viforcos, Pobladura, la Maluenga, Filiel, Combarros, etc.

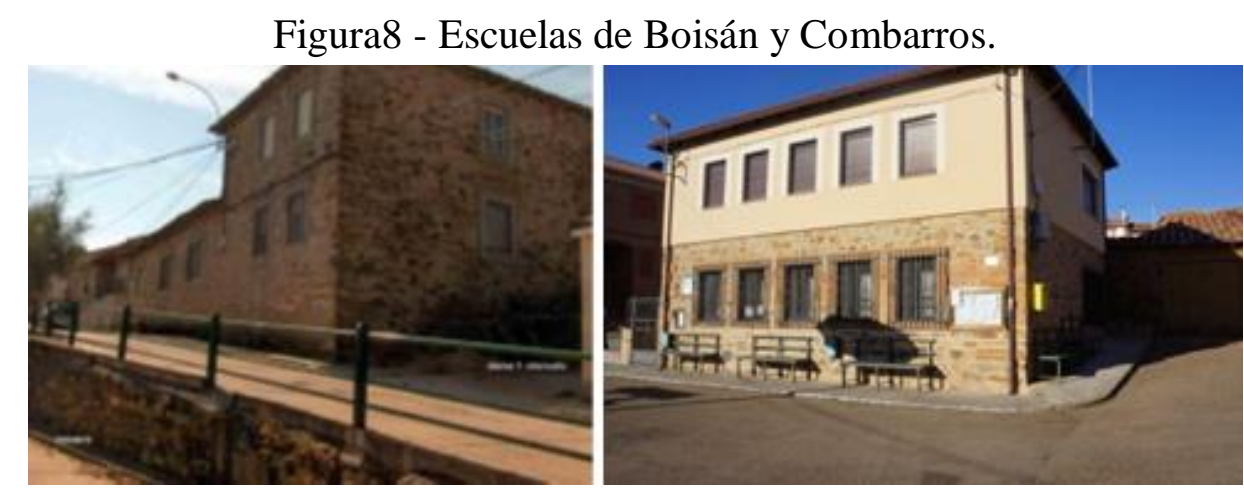

Fuente: Isabel Cantón Mayo.

Figura 9 - Escuela de Rabanal Viejo y Requejo-Pradorrey.
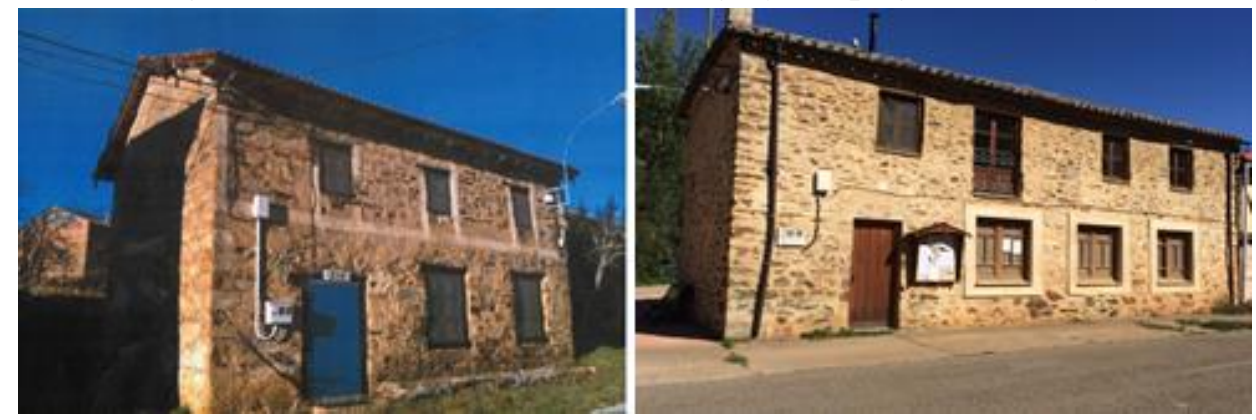

Fuente: Isabel Cantón Mayo y Archivo Histórico de León.

El último grupo cronológicamente son las escuelas construidas en los años 1950 y 1960 acogiéndose a los planes de construcciones escolares del Ministerio de Educación. La posguerra fue una época fructífera en la construcción de escuelas con los sucesivos planes nacionales de Construcciones escolares. Son edificios estándar con dos pisos, el aula en la parte de abajo y la vivienda del maestro en la parte de arriba, ventanales amplios y estructura arquitectónica común. De tipo funcionalista y homogéneo son las que pueden verse en toda la geografía española edificadas en esa época. Algunos pueblos mantienen la vieja escuela dedicada a casa concejo o a local popular, consulta médica y demás, y también la escuela última edificada con el nombre de escuela nueva. La construcción es ahora de ladrillo y están revocadas de cemento, son iguales independientemente del pueblo en el que se ubiquen. Ejemplos: Luyego de Somoza (niñas), 
Viforcos escuela nueva, Rabanal del Camino (también la escuela nueva) Val de San Lorenzo, Veldedo, etc.

Figura 10 - Escuela de Filiel y Escuela de Niñas de Luyego de Somoza.

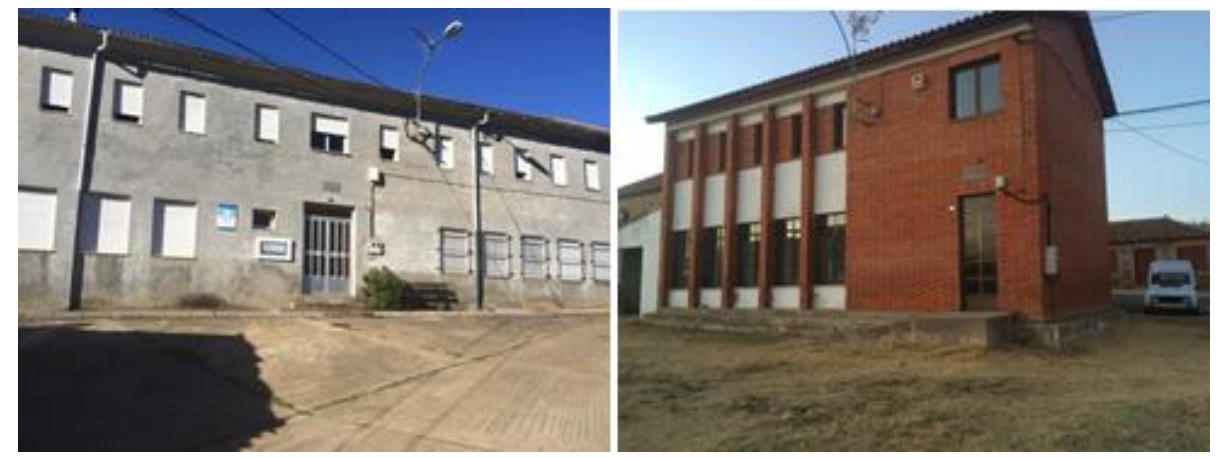

Fuente: Isabel Cantón Mayo y Archivo Histórico de León.

\section{CONCLUSIONES GENERALES}

Las escuelas de una comarca son parte de la historia y de la vida de la misma. La recopilación que se ha hecho para este artículo tiene detrás muchas horas de trabajo de campo, de archivos históricos, nacionales y regionales, de cuidadosa catalogación y de amor por el pasado escolar. En la puesta en valor de lo rural, de lo campesino y de lo lejano, las escuelas constituyen la identidad de un pueblo junto a la iglesia.

La catalogación de los edificios escolares en función de su forma es una aportación, tanto patrimonial como metodológica, ya que implica una diferenciación en función de sus elementos arquitectónicos, de su devenir y de su funcionalidad. Supone una hermeneútica específica dentro de una metodología netamente cualitativa.

La importancia dada a la escuela por los llamados indianos, obedece a una razón práctica: era necesario que los naturales del país supieran leer y escribir para mantener el contacto con los que se habían ido. Pero también la colaboración vecinal aporta y complementa las donaciones de los que se fueron. En muchos casos los pueblos señalan que pusieron la madera y la mano de obra para construir la nueva escuela o mejorar la existente: Murias de Pedredo, Pedredo, Quintanilla de Somoza, etc.

Las escuelas referidas en el $98 \%$ de los casos ya no tienen uso escolar. Solo tres de ellas siguen prestando servicio educativo. Pero justamente la preservación de lo que han sido y de lo que 
han significado durante casi un siglo, supone un reconocimiento a su labor, a su identidad y a su meritoria labor alfabetizadora.

Lo más relevante es el rescate de escuelas que ya no lo son pero lo han sido y reservan la idiosincrasia de la comarca, totalmente singular. Otros trabajos de parecida factura puede verse en Cantón, 1996, 2016 o 1999. Siempre que una escuela se rescata algo nuestro también se conserva en la memoria.

El conocimiento de los edificios escolares tiende a su puesta en valor a su reparación y conservación como patrimonio esencial de los pueblos pequeños y como base para su mejor atención. La escuela es la casa de la socialización y conversión en humanos de los niños, de lugar de igualdad, de solidaridad y de aprendizaje.

\section{BIBLIOGRAFÍA}

ALONSO LUENGO, Luis. Los Maragatos. Madrid: Editorial Nebrija. 1981.

BELLO, Luis. Viaje por las escuelas de España (1926-1929). Madrid: Magisterio Español, 1926.

CALAF MASACHS, Roser. Didáctica del Patrimonio: Epistemología, Metodología y Estudio de casos. Gijón: Trea, 2008.

CAMPOS, Juan Carlos. Petroglifos en Maragatería. El enigma de los laberintos del Teleno. León: Gráficas Celarayn, 2012.

CANTÓN MAYO, Isabel. La Fundación Sierra-Pambley, una institución educativa leonesa. Servicio de Publicaciones de la Universidad de León, 1996.

CANTÓN MAYO, Isabel (Coord.). Las escuelas de la Comarca de La Cepeda. León: Eolas Ediciones, 2016.

CANTÓN MAYO, Isabel. Las escuelas rurales de la Maragatería. León: Eolas Ediciones, 2018.

CANTÓN MAYO, Isabel; PRIETO SARRO, Marta. La Cátedra de latín de Lois. Servicio de Publicaciones de la Universidad de León, 1999.

COSSÍO, Manuel Bartolomé et al. Bases para la construcción de edificios escolares. Madrid: s.e., 1902.

COSSÍO, Manuel Bartolomé. Notas sobre construcción escolar. Madrid: R. Rojas, 1900 y 1911.

Rev. Iberoam. Patrim. Histórico-Educativo, Campinas (SP), v. 05, p. .1-13, e019028, 2019. 
CUENCA, Carlos; FERNÁNDEZ, M. F. Escuelas de indianos y emigrados en Asturias. Gijón: Trea, 2003.

LÁZARO FLORES, Emilio. Historia de las construcciones escolares en España. In: Revista de Educación, n. 240, p. 114-126, 1975.

LUENGO MARTÍNEZ, Jose María. La arquitectura popular de la Maragatería. Ayuntamiento de Astorga, 1995.

MADOZ, Pascual. Diccionario Geográfico-Estadístico-Histórico de España y sus posesiones de ultramar. Tomo sobre León. Edición Facsimil. Valladolid: Ediciones Ámbito, 1845-1850.

RUBIO PÉREZ, Laureano. M. Los maragatos: origen, mitos y realidades. Universidad de León, 2003.

VIÑAO, Antonio. Escolarización, edificios y espacios escolares. CEE Participación Educativa, 7, marzo 2008. p. 16-27.

Recebido em: 11 de junho de 2019

Aceito em: 18 de novembro de 2019 